\title{
Práticas ciberjornalísticas em Realidade Virtual: inovação e impacto nos processos de produção
}

\author{
Cyberjournalistic practices in Virtual Reality: innovation and impact on the \\ production processes
}

\begin{abstract}
Raquel Ritter Longhi
Doutora em Comunicação e Semiótica pela Pontifícia Universidade Católica de São Paulo (2004), é professora no Curso de Jornalismo da Universidade Federal de Santa Catarina (UFSC), onde atua na Graduação e no Programa de Pós-Graduação. Coordenadora do Nephi-Jor - Núcleo de Estudos e Produção em Hipermídia aplicados ao Jornalismo e líder do Grupo de Pesquisa Hipermídia e Linguagem.

$<$ raqlonghi@gmail.com>
\end{abstract}

\section{Alexandre Lenzi}

Doutorando em Jornalismo pela Universidade Federal de Santa Catarina (UFSC), com pesquisa sobre a prática da reportagem multimídia. Tem mestrado em Jornalismo e experiência profissional na área de reportagem e edição de jornal impresso e on-line e em comunicação institucional. Atua, também, como professor de ensino superior desde 2013.

$<$ lenzi.alexandre@gmail.com>

\section{RESUMO}

A produção de conteúdos em Realidade Virtual (RV) marcou o ano de 2016 no ciberjornalismo. Definida também como jornalismo imersivo, essa tendência, que inclui imagens estáticas e em movimento em 360 graus, terceira dimensão e realidade aumentada, entre outros recursos, deve ser incrementada em 2017, em um direcionamento para a inovação nos conteúdos expressivos. Isso é o que apontam várias experiências que têm sido conduzidas nas redações por jornais de referência. A partir de um estudo em duas redações de periódicos de língua espanhola e suas produções inaugurais nesse tipo de conteúdo, este artigo discute o caráter inovador da RV para o jornalismo e suas implicações nos processos de produção. A metodologia inclui uma breve revisão da literatura sobre inovação, jornalismo imersivo e RV, entrevistas com profissionais e descrição de conteúdos selecionados, procurando refletir sobre de que forma o crescimento deste tipo de jornalismo pode transformar os métodos de trabalho e a produção nas redações.

\section{ABSTRACT}

The production of contents in Virtual Reality (VR) marked the year of 2016 in the cyberjournalism. This tendency, also defined as immersive journalism, which includes static images and moving images in 360 degrees, third dimension and augmented reality, among other resources, should be increased in 2017, following the direction of innovation of expressive contents. This is what several newsrooms experiments have indicated. Based on a study of two newsrooms with content in Spanish language, this article discusses the innovative character of VR for journalism and its implications on work and productions processes. The methodology includes a review of the literature about innovation, immersive journalism and VR, interviews with professionals and description of selected contents, with the purpose to think how the growth of this type of journalism can transform work and production methods in newsrooms.

Keywords: Production processes. Virtual Reality (VR). Innovation.

Palavras-chave: Processos de produção. Realidade Virtual (RV). Inovação.

\section{Introdução}

A busca por novos formatos para a apresentação de conteúdos informativos tem sido uma constante nestas mais de duas décadas de jornalismo na internet. Entre as práticas mais recentes, ganha destaque 
a apropriação da Realidade Virtual (RV) em reportagens, configurando exemplos do chamado jornalismo imersivo. Trata-se de uma tendência que pode ser reconhecida como parte da necessária inovação dentro das redações, acarretando mudanças em diferentes frentes, como nos processos de produção, nas tecnologias utilizadas, nos recursos necessários em tempo e dinheiro e, consequentemente, na linguagem final que chega ao público.

Conteúdos expressivos em RV no ciberjornalismo não chegam a ser tão novos: datam pelo menos de 2012, com a incursão pioneira de Nonny De La Peña ${ }^{1}$. Mas foi a partir de 2015 que começaram a desenvolver-se em muitas redações de modo exponencial. Definida também como jornalismo imersivo, essa tendência, que inclui imagens estáticas e em movimento em 360 graus, terceira dimensão e realidade aumentada, entre outros recursos, deve ser incrementada em 2017, beneficiando-se do desenvolvimento tecnológico e da viabilização dos equipamentos de produção e visualização. Isso é o que apontam várias experiências que têm sido conduzidas nas redações, especialmente no caso de grandes jornais.

No Brasil ainda são poucas as iniciativas nesse sentido, restritas a documentários como Rio de Lama, de Tadeu Jungle, sobre o rompimento da Barragem de Mariana, em 2015, que contou com parceria da Folha de S. Paulo, ou a utilização de fotos em 360 graus, como no jornal O Dia (Longhi e Pereira, 2016). Mas, nos Estados Unidos e em países da Europa, a RV tem povoado a produção no ciberjornalismo de referência, como mostram o The New York Times e o The Guardian, entre outros (Longhi, 2016), no que John Pavlik tem definido como "jornalismo experiencial" (Pavlik, 2016). O fato de fazerem parte de um reduzido conjunto de jornais, os chamados veículos de referência, explica-se, entre outras coisas, pelos custos de produção, ainda elevados. Do outro lado, o do leitor, tais conteúdos esbarram na questão da oferta de dispositivos como óculos de Realidade Virtual, necessários para uma maior imersão e cujos custos, neste momento, também estão em desvantagem.

Neste artigo, discutimos o caráter inovador da RV para o jornalismo e suas implicações nos métodos de trabalho e produção por meio de um breve estudo em duas redações de periódicos de língua espanhola. A metodologia inclui uma breve revisão de literatura sobre inovação, jornalismo imersivo e RV, entrevistas com profissionais e descrição de conteúdos selecionados, procurando refletir sobre de que forma o crescimento deste tipo de jornalismo pode transformar as redações.

1 O documentário Hunger in Los Angeles foi lançado em 2012, durante o Festival de Cinema de Sundance, nos EUA, mostrando as potencialidades da RV para o jornalismo. 


\section{Jornalismo experiencial na produção ciberjornalística}

A transformação dos métodos de trabalho e de produção do ciberjornalismo é uma das implicações das tecnologias de Realidade Virtual (RV), como aponta John Pavlik (2016). Para o autor, trata-se de um olhar que necessariamente passa pela questão de quem ou o que é o jornalista, com implicações para outras áreas que incluem conteúdo, estrutura e engajamento público, por exemplo.

Uma potencial transformação do jornalismo com a utilização da RV é analisada pelo autor do ponto de vista do que ele define como a adoção da mídia experiencial (experiential media, também definido como experiential journalism), que inclui pelo menos quatro áreas de impacto: 1 . Produção; 2. Narrativa; 3. Público e 4. Organização. Seccionada por sua vez em duas fases, a da adoção pré-experiencial e a da adoção experiencial, essa matriz mostra impactos conforme o quadro 1 :

\begin{tabular}{|c|c|c|c|c|}
\hline $\begin{array}{l}\text { Virtualidade (RV) } \\
\text { /Ciberjornalismo }\end{array}$ & Produção & Narrativa & Público & Organização \\
\hline $\begin{array}{l}\text { Adoção } \\
\text { pré-experiencial }\end{array}$ & $\begin{array}{l}\text { 2D, câmeras } \\
\text { direcionais, } \\
\text { microfones, } \\
\text { edição } \\
\text { manual, } \\
\text { processos } \\
\text { químicos }\end{array}$ & $\begin{array}{l}\text { Linear, } \\
\text { perspectiva em } \\
\text { terceira pessoa, } \\
\text { publicação/ } \\
\text { emissão fixa }\end{array}$ & $\begin{array}{l}\text { Audiência } \\
\text { passiva, } \\
\text { anônima }\end{array}$ & $\begin{array}{l}\text { Hierárquica, } \\
\text { segura, dirigida } \\
\text { e gerenciada } \\
\text { por humanos }\end{array}$ \\
\hline $\begin{array}{l}\text { Adoção } \\
\text { plenamente } \\
\text { experiencial }\end{array}$ & $\begin{array}{l}\text { Terceira } \\
\text { dimensão } \\
\text { (3D), } \\
\text { câmeras e } \\
\text { microfones } \\
\text { espaciais, } \\
\text { GPS, } \\
\text { dispositivos } \\
\text { móveis, } \\
\text { drones, } \\
\text { ubiquidade, } \\
\text { em rede }\end{array}$ & $\begin{array}{l}\text { Interativo } \\
\text { (não-linear), } \\
\text { imersivo (360), } \\
\text { multissensorial } \\
\text { (visão, som, } \\
\text { toque), fluído } \\
\text { ou dinâmico, } \\
\text { personalizável, } \\
\text { base de dados }\end{array}$ & $\begin{array}{l}\text { Engajada } \\
\text { (participativa) } \\
\text { como } \\
\text { usuários e } \\
\text { colabora- } \\
\text { dores, } \\
\text { conectados } \\
\text { em redes } \\
\text { sociais, } \\
\text { privacidade } \\
\text { em risco }\end{array}$ & $\begin{array}{l}\text { Conectada em } \\
\text { rede, } \\
\text { colaborativa, } \\
\text { guiada por } \\
\text { dados e } \\
\text { algoritmos, } \\
\text { automatizada, } \\
\text { baseada em } \\
\text { nuvem, } \\
\text { segurança em } \\
\text { risco }\end{array}$ \\
\hline
\end{tabular}

Fonte: Pavlik, 2016 (adaptado pelos autores com tradução livre).

O "jornalismo experiencial" (Pavlik, 2016) representa, para o autor, a exploração de conteúdos em RV, muitas vezes em parceria com empresas e 
organizações de tecnologia. Jornais como o The New York Times e o The Guardian apresentaram, no final de 2015 e ao longo de 2016, respectivamente, suas primeiras produções em RV. O The New York Times, além disso, em novembro de 2016 começou a produzir conteúdos diários em vídeo esférico (360 graus), em parceria com a Samsung. No quadro anterior, destacamos as áreas de impacto na fase de adoção plenamente experiencial, que representam em grande parte as formas de adoção das redações analisadas neste artigo.

As ferramentas de produção, nesse caso, são totalmente digitais e desenhadas para capturar imagens em 360 graus, assim como vídeo e som espacial. Essas ferramentas mantêm a integridade espacial das cenas observadas: um quadro contínuo, esférico, ao invés de recortado, por assim dizer.

A narrativa é não linear, imersiva ou em formato de 360 graus; é multissensorial - visão, tato, som - fluida e dinâmica na sua forma. O público é altamente engajado e participativo, como usuário e colaborador. Compartilha ativamente conteúdos pelas redes sociais.

Efetivamente, a produção de conteúdos numa lógica ecossistêmica, conferindo escalabilidade ao processo redacional, é apontada por Beth Saad (2016) entre um conjunto de ações pontuais que estão criando uma relação de proximidade do jornalismo com a inovação.

\section{Inovação no ciberjornalismo}

O incentivo à inovação é, ou pelo menos deveria ser, uma constante em empresas de comunicação. No caso específico do jornalismo, a busca por novos formatos e linguagens diante das possibilidades da internet. Uma necessidade que surge não só diante de crises ou novos concorrentes, mas um processo constante para promover a atualização necessária para conquistar uma nova geração com hábitos e interesses distintos em relação às gerações anteriores. Para Beth Saad (2016, s/n), inovar é inerente à cultura de cada marca jornalística, "às suas crenças e valores relacionados a mudanças, sejam incrementais sejam de ruptura". Para a autora, sempre será possível inovar no jornalismo:

[...] desde que se leve em conta as diferenças de cada organização diante de aspectos como: planejamento estratégico, monitoramento tecnológico, (re)integração da estrutura produtiva para além das redações, conhecimento da audiência e suas mutações constantes, sensibilidade às mudanças no composto de receitas, surgimento de novos competidores etc. (Saad, 2006, s/n). 
Mas esse, obviamente, é um debate que se expande para muitas outras áreas. Ao defender que as próprias empresas e seus modelos organizacionais precisam se tornar inovadores, Thomas M. Koulopoulos (2011) afirma que "em pleno século XXI não há mais lugar para os sistemas utilizados no século anterior, assim como ao século XX os modelos do século XIX também já não mais se aplicavam" (Koulopoulos, 2011, p. 8). E reforça a importância de este ser reconhecido como um processo contínuo: "Inovar é parte do que as grandes organizações fazem todo dia - e não uma vez a cada década, diante de uma crise" (Koulopoulos, 2011, p. 39).

É importante lembrar, também, que a inovação aqui entendida não descarta o passado e as inovações já ocorridas. Não se trata de zerar e recomeçar o processo, mas sim de uma atualização no sentido de um aperfeiçoamento. $E$, nesse sentido, o olhar ao passado, inclusive, contribui muito, como lembra, ao traçar a biografias de diferentes inovadores, o autor Walter Isaacson (2014):

\footnotetext{
A era digital pode parecer revolucionária, mas baseou-se na expansão de ideias legadas por gerações anteriores. A colaboração não ocorreu meramente entre contemporâneos, mas também entre gerações. Os melhores inovadores foram os que entenderam a trajetória da mudança tecnológica e pegaram o bastão de inovadores que os precederam (Isaacson, 2014, p. 494).
}

Em relação especificamente à inovação no jornalismo, os autores espanhóis Francisco J. Pérez-Latre e Alfonso Sánchez-Tabernero (2012) ressaltam a singularidade das empresas de comunicação e a vinculação do destino do setor essencialmente com a evolução tecnológica. Afirmam, ainda, que a resistência à mudança em âmbitos empresariais do setor é um fator quase endêmico, e que, ao tentar identificar exemplos de inovação na comunicação, é preciso distinguir as verdadeiras inovações (novos produtos) de processos de renovações (modificações leves de produtos já existentes).

Na mesma linha, ao estudar a inovação nos meios de comunicação, Charo Sádaba Chalezquer (2016) diferencia duas categorias: a inovação evolutiva, que envolve mudanças dinâmicas e constantes diante dos avanços tecnológicos; e a inovação revolucionária ou descontínua, que é, frequentemente, disruptiva. No caso dos meios de comunicação, entende que houve um primeiro momento revolucionário com a popularização da internet, que proporcionou uma disrupção no modo de produzir, distribuir e consumir conteúdos informativos. Contudo, em uma segunda fase, no contexto atual, lidamos com uma inovação 
evolutiva para responder às mudanças tecnológicas em curso na medida em que elas afetam a rotina das empresas. “Esse processo evolutivo não está isento de pequenas revoluções, como a chegada dos celulares ou tablets, que levantam novamente a necessidade de mudanças mais profundas" (Chalezquer, 2016, p. 424, tradução nossa²). E, para impulsionar estas mudanças profundas, o autor destaca, entre outros fatores, o papel da liderança dentro da empresa:

É certo que as empresas de mídia ainda sofrem em alguns casos com estruturas organizacionais um pouco descompensadas e que precisam de reajustes para torná-las sustentáveis. Mas parece claro que precisam de uma liderança real e de uma autêntica troca de cultura e criatividade organizacional para convencer da necessidade de enfrentar as mudanças, que incluem não apenas ajustes, mas também investimentos, a fim de garantir o presente e, acima de tudo, ganhar o futuro (Chalezquer, 2016, p. 432, tradução nossa ${ }^{3}$ ).

Para Saad (2016, s/n), a inovação no jornalismo refere-se a uum contínuo e resiliente movimento de adequação diante da mutação dos processos cognitivos da sociedade e diante do impacto desta adequação no papel de legitimação exercido pelo jornalismo".

No atual cenário, é inegável que a internet possibilitou novos formatos de apresentação do material jornalístico e, consequentemente, transformou o processo de produção do conteúdo apurado, em busca tanto de inovações quanto de renovações. Aproveitando o espaço ilimitado e o potencial da linguagem multimídia, entre outras características da web, passou-se produzir conteúdo jornalístico pensado especificamente para o ambiente on-line. Mas ainda vivemos um período de experimentação e testes em redações mundo afora, depois de anos apenas replicando no meio on-line o que se fazia em outras plataformas. E agora a prática da Realidade Virtual aliada à reportagem ganha destaque nesse contexto.

O pesquisador espanhol José Luis Orihuela (2015) identifica quatro pontos essenciais para entender a mudança nos meios depois da internet. $O$

2 No original: Este proceso evolutivo no está exento de pequeñas revoluciones, como la llegada de los móviles o de las tabletas, que plantean de nuevo la necesidad de cambios más profundos. 3 No original: Es cierto que todavía las empresas de medios adolecen en algunos casos de estructuras organizativas un tanto descompensadas y que precisan de reajustes que las hagan sostenibles. Pero parece más claro que precisan de liderazgo real, y de un auténtico cambio de cultura y creatividad organizativas que les convenza de la necesidad de afrontar cambios, que incluyen no solo ajustes sino también inversión, con el fin de asegurar el presente pero, sobre todo, ganar el futuro. 
primeiro consiste em reconhecer que o impacto das inovações em tecnologias da comunicação é um processo permanente. A novidade agora está na velocidade do processo, mais acelerado, e na consequente dificuldade por parte das empresas para assimilar as mudanças. O segundo ponto está no fato de que esse é um cenário irreversível. "Embora ninguém possa saber o que o futuro nos reserva, podemos ter a certeza de que não há retorno ao modelo de comunicação analógica do passado" (Orihuela, 2015, p. 60, tradução nossa4). O terceiro aspecto está na necessidade de diferenciar o futuro dos meios, as tradicionais empresas de comunicação de massa, do futuro do jornalismo, entendido como profissão e função social. Para o autor, pode não existir certeza quando ao futuro empresarial, mas existe, sim, quanto à necessidade do segundo em uma sociedade democrática.

Porúltimo, Orihuela (2015) defendequeépreciso apostarna especialização para que ojornalismo possa distinguir-see competir em um cenário caracterizado pelo acesso indiscriminado às plataformas de comunicação proporcionado pela internet. "Se todo mundo pode opinar sobre qualquer tema em qualquer plataforma pública, então as marcas jornalísticas (empresariais e pessoais) têm que diferenciar-se pela excelência dos seus conteúdos" (Orihuela, 2015, p. 60, tradução nossa ${ }^{5}$ ). Nesse sentido, é preciso aprender a fazer as coisas sempre de uma maneira diferente e, principalmente, aprender a fazer coisas novas.

O autor evidencia, assim, a importância dos novos conteúdos, defendendo que, sem produtos de qualidade, diferenciados e originais, não há negócio possível a longo prazo. O desafio dos meios, nesse sentido, é se diferenciar não pelas plataformas, mas sim pelo prestígio de suas marcas. E para isso é preciso incorporar a inovação de forma permanente na cultura organizacional, motivando a equipe profissional. "Estou convencido de que existe um futuro para o jornalismo e para os jornalistas, mas não para qualquer jornalismo nem para todos os jornalistas. Inovar é uma questão de sobrevivência" (Orihuela, 2015, p. 121-122, tradução nossa ${ }^{6}$.

O processo de inovação tem se repetido ao longo dos anos. Ao estudar os meios de comunicação diante de outros momentos de renovação tecnológica, Marshall McLuhan (1979) já afirmava que o meio é a mensagem, ou seja, um novo ambiente transforma a mensagem em relação ao modelo praticado até

4 No original: "Aunque nadie puede saber cómo será el futuro, podemos tener la certeza de que no hay vuelva atrás al modelo de comunicación analógico del pasado".

5 No original: "Si todo el mundo puede opinar acerca de cualquier tema en cualquier plataforma pública, entonces las marcas periodísticas (empresariales y personales) tienen que diferenciarse por la excelencia de sus contenidos".

6 No original: "Estoy convencido de que hay futuro para el periodismo y los periodistas, pero no para cualquier periodismo ni para todos los periodistas. Innovar es una cuestión de supervivencia”. 
então. Trata-se de um movimento contínuo de evolução, não necessariamente de substituição, e que no caso da produção on-line multimídia ainda enfrenta uma série de testes e de adaptações de linguagens e também de processos produtivos. Mas um movimento que não pode mais ser ignorado.

Caio Túlio Costa (2014) defende que as empresas responsáveis por um novo jornalismo terão que optar por desenvolver projetos em plataformas que não sabem se darão certo. Faz parte do jogo, aponta, ao mesmo tempo em que defende que os riscos existentes não podem limitar a inovação, fundamental para uma evolução contínua na linguagem do jornalismo on-line.

Antes mesmo de recursos como a RV ganharem força, Philip Meyer (2007) também já enxergava na inovação tecnológica uma possibilidade para que os jornais pensassem em novas aplicações e agregassem valor aos seus conteúdos. "Novas tecnologias criam novos clientes que os negócios já estabelecidos, focados em defender seus mercados, tendem a ignorar. Crescendo a partir desses novos mercados, os novos negócios por fim passam a competir com os já estabelecidos" (Meyer, 2007, p. 232).

George Brock (2013) enxerga um futuro para o jornalismo na combinação das organizações hoje existentes com os novos participantes desse cenário. $E$, para alcançar uma combinação ideal, o caminho sugerido é o da experimentação constante, sendo que, mais de duas décadas depois da popularização da internet, oportunidades e possibilidades ainda estão sendo criadas:

[...] o sucesso ou o fracasso será determinado pela quantidade e pela qualidade de experiências para descobrir o que funciona. Ojornalismo tem crescido e se feito útil por meio da experimentação. Jornalistas devem agora experimentar novamente a fim de reconstruir o seu papel em um sistema de informação em mudança. [...] Ser obrigado a rever princípios básicos só pode ajudar. Jornalismo pode florescer em uma nova era da comunicação. Para preservar o que é importante, muito tem que mudar (Brock, 2013, p. 5, tradução livre).

7 No original: "[...] Success or failure will be determined by the quantity and quality of experiments to find out what works. Journalism has grow and made itself useful through experimentation. Journalists must now experiment again in order to rebuild their role in a changing information system. [...] Being obliged to revisit basic principles can only help. Journalism can flourish in a new communications age. To preserve what's important, much has to change". 


\section{Jornalismo imersivo}

O termo "jornalismo imersivo" vem sendo usado amplamente para definir a produção de conteúdos em RV, contendo, principalmente, imagens e vídeos em 360 graus, também chamados de "esféricos". Na definição de Nonny De La Peña, trata-se da "produção de notícias de forma que os leitores/usuários possam ter experiências em primeira pessoa de eventos ou situações descritas em narrativas jornalísticas" (De La Peña, citado por Longhi, 2016).

O interesse em transportar o leitor para o local da história, ou do acontecimento, porém, não é novo, conforme Longhi: já se fazia presente na literatura, no cinema e em outras artes, sendo apropriado pelo jornalismo mais recentemente:

Desde que os videogames popularizaram a ideia de imersão em mundos virtuais, quando o termo Realidade Virtual passou a ser mais conhecido do grande público, o jornalismo vem buscando maneiras de fortalecer esse tipo de conteúdo narrativo. Isso foi alcançado especialmente depois que o ambiente hipermidiático e on-line do webjornalismo proporcionou maiores possibilidades, tanto tecnológicas, quanto expressivas (Longhi, 2016, p. 5).

Ainda que não se trate de algo totalmente inédito, a ideia de imersão carrega consigo um potencial inovador, mesmo que existam controvérsias sobre a eficácia da imersão em tais conteúdos, como observa o professor e pesquisador Ramón Salaverría, em entrevista aos autores. Ele defende que as tecnologias de Realidade Virtual têm um potencial grande para a exploração jornalística, mas relativiza o conceito de imersão:

O verdadeiramente imersivo em uma história jornalística não é sua apresentação gráfica, mas sim sua estrutura narrativa. Antes que chegassem todas as tecnologias atuais, tínhamos exemplos de textos em que você consegue arrastar o leitor para dentro de uma história. Para mim, isso é imersivo de verdade (Salaverría, 2016).

Apesar de as atuais tecnologias permitirem um tipo de imersão de uma forma muito mais "impactante", por situar o leitor "dentro de uma cena" física e sensorialmente, salienta Salaverría, isso não significa que se está contando melhor uma história. Aqui reside o ponto da questão: o uso da tecnologia, por si só, não garante a qualidade. Na verdade, essa é uma observação que se aplicava, 
também, quando a exploração dos recursos hipermidiáticos e multimídia pelo jornalismo dava seus primeiros passos, na segunda metade dos anos 1990 e na primeira dos 2000.

Para o autor espanhol:

[...] no atual momento, não se domina suficientemente esta tecnologia como para contar histórias com o grau de profundidade que podes contar com um texto plano. Um escritor pode te levar a um cenário com mais intensidade e com maior profundidade do que uns óculos que te situam em um entorno um tanto alienante. Insisto, me parece que têm potencial para chegar a esse cenário. $E$, se nesse momento tens capacidade de combinar essa intensidade e profundidade narrativa com essa potência sensorial, tua capacidade de gerar uma experiência imersiva é muito maior. [...] Mas atualmente me parece que existe muito mais narrativa imersiva fora da tecnologia virtual do que dentro (Salaverría, 2016).

\section{Primeiras experiências em espanhol}

Exemplos de quem já aderiu à tendência do jornalismo imersivo, o argentino Clarín e o espanhol El País apresentaram seus primeiros produtos em $R V$, respectivamente, em abril e em maio de 2016, anunciando-se pioneiros na prática no idioma espanhol. Tais produções de conteúdos inaugurais em veículos de língua espanhola e suas implicações no cenário atual do ciberjornalismo são aqui estudadas por meio de entrevistas com profissionais das duas redações envolvidas e da descrição de conteúdos selecionados ${ }^{8}$.

O argentino Clarín, que na primeira década de 2000 destacou-se de forma pioneira com publicações de reportagens multimídia premiadas internacionalmente, busca mais uma vez sair na frente dos concorrentes. Em abril de 2016, foi lançado o aplicativo do Clarín para Realidade Virtual, disponível para Android e iOS. Parte dos conteúdos também pode ser acessada por smartphones, mas é por meio de dispositivos como o Google Cardboard ou o Samsung Gear que o público tem a experiência completa com a Realidade Virtual.

Entre as primeiras reportagens, está "ESMA: sobrevivientes del infierno", sobre vítimas da ditadura argentina que foram aprisionadas e torturadas na década de 1970 na então Escuela de Mecánica de La Armada, hoje transformada em Espacio Memoria y Derechos Humanos, mantendo a mesma sigla. O material

8 A visita aos periódicos El País e El Mundo fez parte do estágio de um dos autores como pesquisador visitante do Center for Internet Studies and Digital Life, da Universidade de Navarra, Pamplona, Espanha, entre outubro e dezembro de 2016. O periódico argentino Clarín foi incluído na pesquisa como representante do cenário latino-americano. 
apresentado em RV intercala cenas com narração, depoimentos e animações, integrando um vídeo com cerca de sete minutos de duração.

Em artigo publicado em abril de 2016 apresentando o aplicativo, o editorchefe Darío D’Atri é enfático ao afirmar que se trata de um conteúdo jornalístico:

[...] é jornalismo em evolução e transformação. Muda a forma de contar a realidade, simplesmente porque a experiência do usuário, antigo leitor, é uma experiência de imersão total no âmbito da história, na realidade narrada (D'Atri, 2016, tradução nossa9).

O jornalista defende que a união entre tecnologia e jornalismo é a chave para entender a transformação no consumo da informação e, nesse contexto, entende que os novos softwares e hardwares como os que permitem a experiência em Realidade Virtual são um desafio para a atividade jornalística.

Afirma D'Atri, no mesmo artigo: “O (aplicativo) Clarín VR é por isso um enorme desafio, o de inventar uma nova maneira de dizer a realidade [...]. É contar e viver o contado" (D'Atri, 2016, tradução livre ${ }^{10}$ ).

"ESMA: sobrevivientes del infierno" é apresentada como uma reportagem em Realidade Virtual e, realmente, tem os elementos necessários para ser assim enquadrada. Para citar apenas alguns recursos comuns ao tradicional gênero jornalístico, o material conta com levantamento histórico em profundidade, entrevistas e contextualização.

\section{Figura 1 - Reportagem “ESMA: sobrevivientes del infierno”, do Clarín}

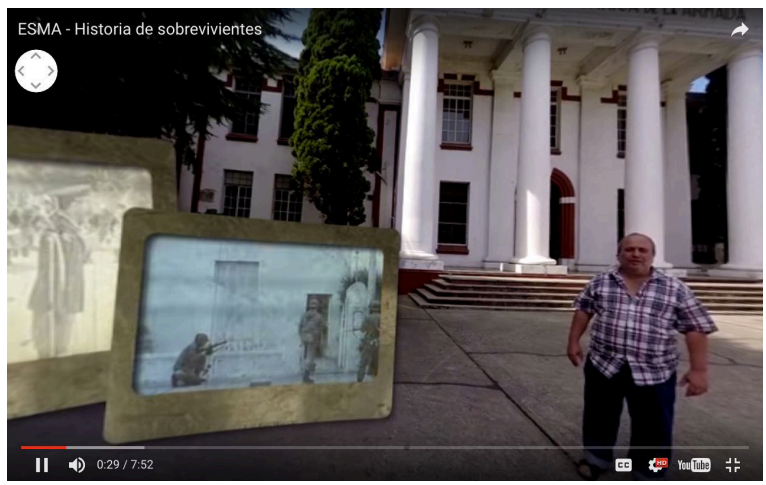

Fonte: captura de tela pelos autores.

$9 \quad$ No original: "[...] es periodismo en evolución y transformación. Cambia de plano la forma de contar la realidad, sencillamente porque la experiencia del usuario, antiguo lector, es una experiencia de inmersión total en el ámbito de la historia, en la realidad narrada".

10 No original: "Clarín VR es por eso un enorme desafío, el de inventar una nueva manera de decir la realidad [...] Es contar y vivir lo contado”. 
Mas o aplicativo Clarín VR também apresenta vídeos temáticos, nem sempre necessariamente reportagens. O público pode conferir, por exemplo, um passeio pelo ponto turístico El Caminito, onde o vídeo em Realidade Virtual traz elementos como música e narração, mostrando belezas do local, mas sem entrevistas ou informações contextualizadas sobre o local.

Poucas semanas depois da estreia do Clarín RV, o espanhol El País publicou "Fukushima, vidas contaminadas", em $1^{\circ}$ de maio de 2016, inaugurando o canal do jornal que explora recursos em Realidade Virtual.

Até novembro de 2016, o concorrente direto do El País, o jornal El Mundo ainda não havia lançado conteúdos em Realidade Virtual e nem tinha previsão para fazê-lo, diante dos altos custos de produção e do público limitado, como informou em entrevista em 20 de outubro de 2016 o subeditor do El Mundo.es, Vicente Ruiz. A perspectiva, até então, era buscar algum tipo de parceria com uma produtora terceirizada, mas nada havia de concreto nesse sentido.

O trabalho do El País abordou a rotina de quem vive na região do Japão marcada pela tragédia em 2011, quando um terremoto seguido de um tsunami provocou um vazamento radioativo na usina nuclear local. O jornalista Daniel Verdú trabalhou ao lado de uma equipe terceirizada que produziu o conteúdo.

$\mathrm{Na}$ época, mais de 100 mil pessoas foram evacuadas. Cinco anos depois, milhares de japoneses ainda vivem em barracões sob a ameaça da radiação, conforme dados da reportagem. Segundo artigo publicado pelo jornal na véspera da publicação, uma equipe de seis pessoas viajou ao Japão em fevereiro de 2016 e passou uma semana gravando os cenários em 360 graus, incluindo a produção de fotografias tridimensionais.

\section{- Figura 2 - “Fukushima, vidas contaminadas”, do El País}

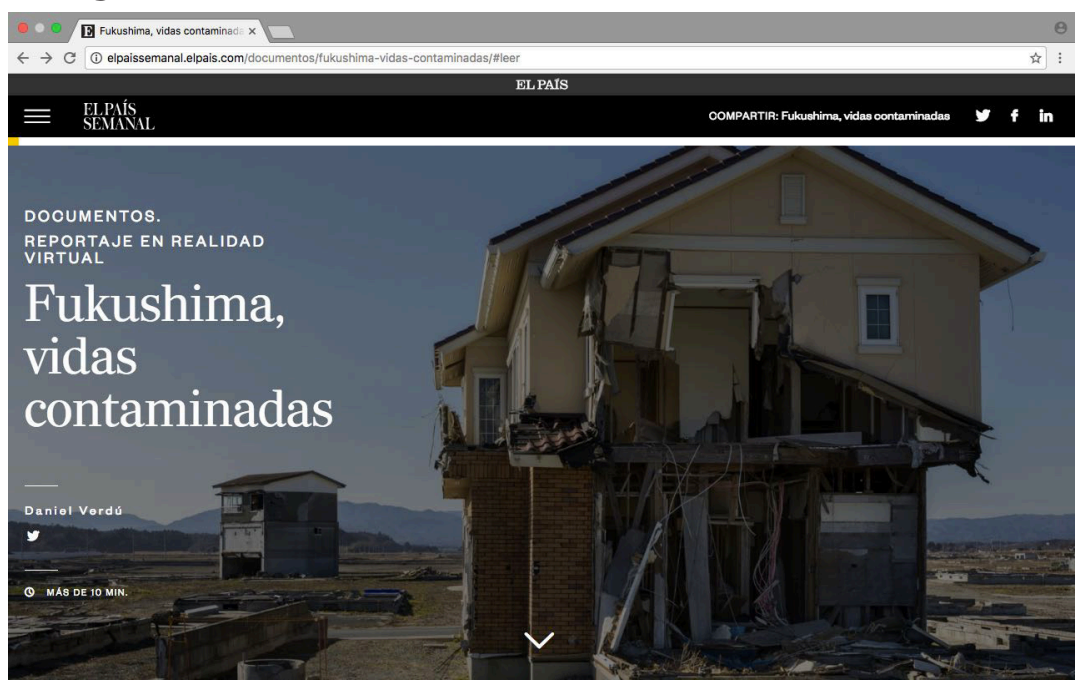

Fonte: captura de tela pelos autores. 
A versão em texto e fotos da reportagem "Fukushima, vidas contaminadas" foi publicada no site do El País, e o vídeo em RV, com 9 minutos e 19 segundos de duração, pode ser acessado pelo site ou pelo aplicativo El País RV. No site, o público é direcionado para o canal do YouTube. Ao acionar o vídeo, um cursor no canto esquerdo superior da tela permite que o público conduza a imagem em movimentos em 360 graus, para cima ou para baixo, para a esquerda ou a direita. O material conta com narração em tom documental, depoimentos e uma animação reconstruindo o acidente.

$\mathrm{O}$ texto tem 3 mil palavras, aproximadamente 17,7 mil caracteres, contando os espaços, o que caracteriza o formato longform (Longhi, 2014). A mesma página apresenta fotos, e há um banner publicitário no canto inferior direito ao longo de toda a reportagem. Ao final, existe a opção de compartilhar o conteúdo pelo Facebook, pelo Twitter ou pelo Linkedin.

\section{Figuras 3 e 4 - Entrevistas na reportagem "Fukushima, vidas contaminadas"}
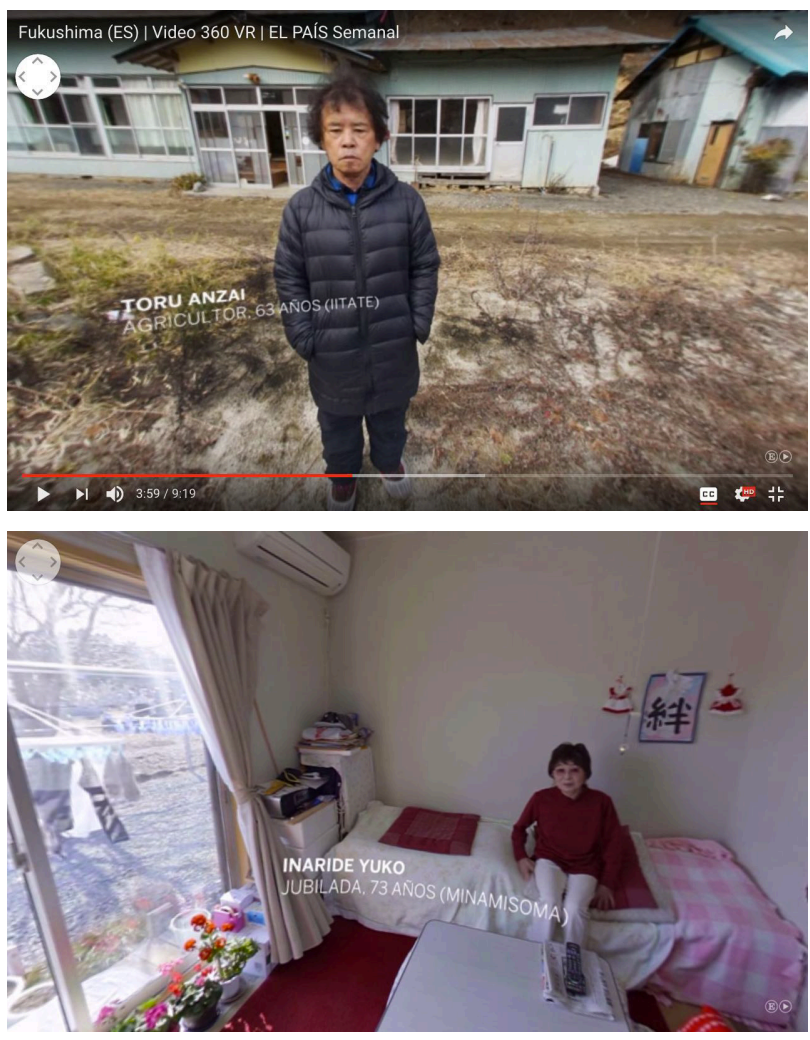

Fonte: capturas de tela pelos autores.

Pelo aplicativo EI País VR para celular, disponível para Android e iOS, além de ver o vídeo como no YouTube, é possível utilizar óculos compatíveis com o Google Cardboard para uma experiência mais imersiva. Para o que o jornal define como "imersão total", é recomendado utilizar óculos como o Samsung Gear VR e 
os Oculus Rift, que são conectados ao celular e ao computador, respectivamente. O repórter Daniel Verdú assina o texto do site e a ideia e o roteiro do vídeo, dois fotógrafos assinam as fotos e a produção audiovisual é da New Horizons VR.

Em visita à redação do El País, no dia 19 de outubro de 2016, foram entrevistados profissionais envolvidos com a produção. Para o repórter Daniel Verdú, fazer o especial foi como fazer duas reportagens diferentes. Uma, de forma tradicional, para o jornal impresso. E outra, com a produção em Realidade Virtual, para o site e o aplicativo El País RV. Para a primeira, diz que fez o trabalho de um jornalista tradicional e, para a segunda, trabalhou como uma espécie de um guia para os produtores.

Como a câmera grava em todas as direções, é preciso teatralizar um pouco as entrevistas. Então, primeiro fiz as entrevistas tradicionais, perguntei tudo o que queria saber para escrever a reportagem. Depois, com a participação dos produtores, pedia para refazer parte da entrevista, encenando um pouco algumas situações (Verdú, 2016).

Para o jornalista, a grande vantagem da RV é criar uma maior empatia por parte do público com os personagens da história.

O espectador está, literalmente, dentro da história, vivendo um pouco da realidade dessa gente. E uma das funções principais do jornalismo é fazer as pessoas vivenciarem as histórias relatadas. A RV ajuda muito nisso. Mas, como os outros recursos do jornalismo, é preciso ser usado com cuidado para não virar espetáculo. Esse é o maior perigo. Mas esse risco também existe em outros meios (Verdú, 2016).

\section{Perspectivas}

Embora ainda em caráter de experimentação, os resultados obtidos com as reportagens aqui analisadas foram comemorados pelas respectivas redações ao ponto de seus gestores indicarem planos para continuar apostando em produções envolvendo Realidade Virtual nos cenários de médio e longo prazo.

Não foram, no entanto, divulgados dados sobre a audiência dos especiais, e há um reconhecimento de que o público ainda pode ser aumentado significativamente. Em entrevista aos autores por e-mail em novembro de 2016, o editor-chefe do Clarín, Darío D'Atri, afirma que, ao desafio de se encontrar novos formatos narrativos, soma-se a reflexão sobre o alcance dos conteúdos 
apresentados em RV, que considera ainda limitado, com exceção das peças em 360 graus divulgadas via Facebook. Para o jornalista, é necessário:

[...] equilibrar a ansiedade que temos como produtores de conteúdos com a escassa penetração que, ao menos na Argentina, têm os celulares capazes de reproduzir em alta qualidade vídeos de Realidade Virtual, e a baixa quantidade de cardboards e de outros dispositivos de visualização (D’Atri, 2016).

No El País, a proposta é ampliar cada vez mais o espaço para novas experiências com Realidade Virtual. Em entrevista aos autores, a chefe de inovação do jornal espanhol, Guiomar del Ser, afirma que a Realidade Virtual permite uma profundidade até então impensável, ampliando a percepção da informação. "Algo que me parece fascinante porque tem tantas possibilidades que ainda não encontramos todas as formas de explorá-las adequadamente. Temos que trabalhá-las com muitíssimo interesse e muita criatividade" (Ser, 2016, tradução livre).

E o subdiretor de canais digitais do El País, Bernardo Marín, confirma o interesse em continuar explorando o formato:

São muitas possibilidades expressivas para os jornalistas. Fizemos essas primeiras experiências no El País e nos saímos bem. É uma perspectiva nova e muito surpreendente para o leitor que nunca tenha visto. Vamos fazer novas experiências, sem dúvida (Marín, 2016).

\section{Considerações finais}

É inegável a necessidade de inovação para jornais tradicionais fazerem frente aos novos concorrentes e conquistarem público em suas plataformas digitais. Em alguns casos, como o da incorporação da Realidade Virtual à narrativa jornalística, é preciso muito mais do que disposição e interesse em inovar, diante da exigência de investimentos consideráveis em tempo e dinheiro para produções desse porte.

Perceber que jornais como Clarín e El País contam com gestões que unem tanto a disposição em inovar como condições financeiras é, no mínimo, confortador ao pensar o futuro do jornalismo. Os temas para os primeiros especiais aqui analisados também merecem ser ressaltados, apresentando 
inegáveis atrativos do ponto de vista jornalístico, independentemente do meio em que a reportagem é publicada. Diante desse quadro, mesmo que a prática da RV não se consolide como recurso comum nas redações, o pioneirismo e a ousadia daqueles que experimentaram demonstram uma equipe atenta a tendências de mercado.

Contudo, não se pode ignorar questões como as levantadas pelo próprio repórter do El País, Daniel Verdú, que alerta para o risco de espetacularização; ou pelo professor Ramón Salaverría, que relativiza a capacidade de imersão das experiências em RV no jornalismo. A inovação, nesse caso tecnológica e, consequentemente, de formato jornalístico, pode ser um forte aliado para contar boas histórias, desde que trabalhada de forma conjunta com características que acompanham a atividade ao longo da história, como veracidade e relevância, para citar apenas algumas clássicas.

Consideradas inovadoras, tais narrativas seguramente terão impacto sobre os modos de produção e de trabalho nas redações jornalísticos. Ao lado desta (quase) certeza, entretanto, fica uma pergunta, já manifestada no "Relatório sobre jornalismo imersivo viewing the future", produzido pelo Knight Center em março de 2016: o jornalismo em RV é apenas uma onda ou veio para ficar? Salvo essa questão, parece certa a tendência de que, neste ano de 2017, a RV continuará sendo objeto de produção de conteúdo, provavelmente sendo amplianda para mais periódicos e países diante dos avanços tecnológicos e de uma maior oferta de equipamentos de produção e visualização.

\section{Referências}

"Bem-vindos ao jornalismo imersivo". Publicado por El País em 29 de abril de 2016. Disponível em: https://goo.gl/bFx9pr. Acesso em: 10 nov. 2016.

BROCK, George. Out of print: newspapers, journalism and the business of news in the digital age. Londres e Filadélfia: Kogan Page, 2013.

CHALEZQUER, Charo Sádaba. Innovación en el sector de los medios. In: SALAVERRÍA, Ramón (Org.). Ciberperiodismo en Iberoamérica. Barcelona e Madri: Editorial Ariel e Fundación Telefónia, p. 423-434, 2016.

COSTA, Caio Tulio. Um modelo de negócios para o jornalismo digital. Revista de Jornalismo ESPM, São Paulo, v. 9, p. 51-115, abr./maio/jun. 2014.

D'ATRI, Darío, editor-chefe do Clarín. Entrevista por e-mail aos autores. Concedida em 10 nov. 2016. 
D'ATRI, Darío. Periodismo, sin importar la plataforma. Clarín, Buenos Aires, 3 de abril de 2016. Disponível em: http://www.clarin.com/sociedad/Periodismoimportar-plataforma 0 1550845186.html. Acesso em: 12 nov. 2016.

DOYLE, Patrick; GELMAN, Mitch; GILL, Sam. Viewing the future? Virtual reality in journalism. Miami (EUA): Knight Foundation, 2016.

"ESMA: sobrevivientes del infierno". Publicado por Clarín em 10 abril de 2016. Disponível em: http://www.clarin.com/sociedad/ESMA-realidad-virtual-ClarinVR 0 1555644718.html. Acesso em: 22 nov. 2016.

"Fukushima, vidas contaminadas". Publicado por El País em $1^{\circ}$ de maio de 2016. Disponível em: http://elpaissemanal.elpais.com/documentos/fukushima-vidascontaminadas/\#leer. Acesso em: 25 nov. 2016.

HUNGER in Los Angeles. Direção: Nonny De La Peña. Nova lorque (EUA): Emblematic Group, 2012. (3min.), son., color., arquivo digital. Disponível em: https://www. youtube.com/watch?v=SSLG8auUZKc. Acesso em: 20 jan. 2017.

ISAACSON, Walter. Os inovadores: uma biografia da revolução digital. São Paulo: Companhia das Letras, 2014.

KOULOPOULOS, Thomas M. Inovação com resultado: o olhar além do óbvio. São Paulo: Editora Gente/Editora Senac, 2011.

LONGHI, Raquel Ritter. O turning point da grande reportagem multimídia. Revista Famecos, Porto Alegre, v. 21, n. 3, p. 897-917, set./dez. 2014.

LONGHI, Raquel Ritter. Narrativas imersivas no webjornalismo: entre interfaces e Realidade Virtual. In: SBPJor, 2016, Palhoça. 14 Encontro Nacional de Pesquisadores em Jornalismo. Palhoça: Unisul, 2016. v. 1. p. 108. Disponível em: http://migre.me/vX7yH. Acesso em: 23 nov. 2016.

LONGHI, Raquel Ritter; PEREIRA, Sílvio da Costa. Do panorama à Realidade Virtual: como o ciberjornalismo está criando narrativas imersivas. In: Alaic 2016, Cidade do México. Memorias XIII Congreso Latinoamericano de Investigadores de la Comunicación. Cidade do México: Universidad Autónoma Metropolitana, 2016, p. 165-172. Disponível em: https://goo.gl/ZktXXp. Acesso em: 23 nov. 2016.

MARÍN, Bernardo, subdiretor de canais digitais do El País. Entrevista aos autores. Concedida em 19 de outubro de 2016.

MCLUHAN, Marshall. Os meios de comunicação como extensões do homem. 5 ed. São Paulo: Cultrix, 1979.

MEYER, Philip. Os jornais podem desaparecer? São Paulo: Contexto, 2007.

ORIHUELA, José Luis. Los medios después de internet. Barcelona: Editorial UOC, 2015. 
PAVLIK, John. The rise of virtuality: transforming cyberjournalism through experiential journalism. Palestra proferida no $7^{\circ}$ Congresso Internacional de Ciberjornalismo. Campo Grande, 2016.

PÉREZ-LATRE, Francisco J.; SÁNCHEZ-TABERNERO, Alfonso. Innovación en los medios: la ruta del cambio. Navarra (Espanha): Ediciones Universidad de Navarra (EUNSA), 2012.

RIO de Lama. Direção: Tadeu Jungle. São Paulo: Academia Filmes, Beenoculos e Maria Farinha Filmes, 2016. (9min.), son., color., arquivo digital. Disponível em: https:// www.youtube.com/watch?v=7zQZqqSkJq0. Acesso em: 20 jan. 2017.

SAAD, Beth. A impermanência do jornalismo diante da inovação. Observatório da Imprensa, ed.927, dez.2016, s/n. Disponível em: http://observatoriodaimprensa. com.br/imprensa-em-questao/impermanencia-do-jornalismo-diante-dainovacao. Acesso em: 1 dez. 2016.

SALAVERRÍA, Ramón, professor e pesquisador na Universidade de Navarra, Pamplona, Espanha. Entrevista aos autores. Concedida em 3 nov. 2016.

SER, Guiomar del, chefe de Inovação do El País. Entrevista aos autores. Concedida em 19 out. 2016.

VERDÚ, Daniel, repórter do El País. Entrevista aos autores. Concedida em 19 out. 2016.

Encaminhado em: 7/3/2017

Aceito em: 15/5/2017

Endereço dos autores:

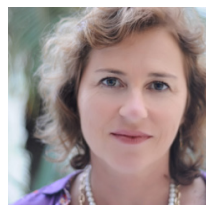

Raquel Ritter Longhi <raqlonghi@gmail.com>

Universidade Federal de Santa Catarina (UFSC)

Campus Universitário - Trindade

88040-970 - Florianópolis (SC) - Brasil

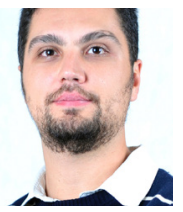

Alexandre Lenzi <lenzi.alexandre@gmail.com>

Universidade Federal de Santa Catarina (UFSC)

Campus Universitário - Trindade

88040-970 - Florianópolis (SC) - Brasil 